\title{
ECONOMIC EVALUATION OF GROCERY STORE NETS IN CITIES - A MODEL APPROACH
}

\author{
M. HARALDSSON \& T. SVENSSON \\ VTI, Sweden.
}

\begin{abstract}
The rapid transformation of the grocery business in cities from small to larger units during the last decades has resulted in grocery store nets with fewer nodes. Cost reductions as well as cost increases associated with the structural change are present, with a poorly understood net effect. Earlier research indicates that retail trade is subject to an increasing-returns illusion when increasing consumer participation in performing the service reduces the amount of service actually performed by the firm. This is still to a large extent an unexplored issue of utmost policy relevance. In this paper a total cost model will be presented that focuses on this research question. Its components, grocery prices in retailing and consumers transport cost functions, are estimated from empirical data and derived from a specific spatial structure respectively. Our conclusion is that the increasing returns are not an illusion but due to external costs somewhat exaggerated. The costs associated with the transport and time use by consumers are more than well compensated by the scale economies related to larger stores. When the transport network is severely congested, however, we have a situation closer to the scenario with an increasing-returns illusion. But we can clearly state that the structural change in grocery retailing is welfare enhancing when the capacity utilization in the transportation system is balanced. From a policy perspective the results of this study clearly suggest that issues regarding local service should be an integral part of strategic urban transport planning. With infrastructure and transportation systems that enable easy and affordable access with cars in the city, a significant number of people will find it optimal to use large stores for grocery shopping. Restrictive policies at the more detailed level, currently applied in many countries, will clearly be ineffective since they are counteracted by forces released by more strategic choices.
\end{abstract}

Keywords: consumer transport costs, grocery stores, increasing returns illusion, urban transport.

\section{INTRODUCTION}

The rapid transformation of the grocery business from small to larger units during the last decades has resulted in grocery store nets with fewer nodes. Another implication is a more diversified network, with several types of stores [1]. Generally, the spatial concentration has resulted in more efficient in-firm distribution. With grocery distribution being an increasing-returns industry, large stores offer comparatively low prices [2], which of course benefit consumers. On the other hand, consumers are facing increasing average distances to their closest store. Consequently, a larger share of the grocery distribution, both in terms of time and distance, is undertaken by consumers. Hence, cost reductions as well as cost increases associated with the observed structural change are present, with a poorly understood net effect. Ofer [3] claims that retail trade is subject to an increasing-returns illusion when increasing consumer participation in performing the service reduces the amount of service actually performed by the firm. This is still, to a large extent, an unexplored issue of utmost policy relevance. It is far from obvious whether the spatial concentration is a result of optimal 'invisible hand' decisions or the failure of the market to create socially optimal distribution systems. Since some cost components are increasing while others are decreasing, we have an intricate optimization problem where complexity is added by the store type diversity discussed above. It is a historical irony that few attempts to solve this problem have been made during a period when grocery distribution has been dramatically transformed, leaving planners and policy makers with a fragmented and less than sufficient basis for decision making. 
To the best of our knowledge recent literature does not include realistic analyses of these questions. Literature about the grocery sector is generally focused on single aspects, leading to one-dimensional policy recommendations. There is quite comprehensive literature on more separate topics such as consequences for private car transports and application of planning policies relevant to grocery industry (for a review of international literature, see Hagson [4]). Focusing on such problems, urban centre deterioration etc. would result in more restrictive planning policies, limiting the number of larger stores and specifically out-of-town establishments. Such policies have for instance been used in Norway and Denmark [5]. In the economic field focus has been on industrial organization, i.e. industrial structure and competition, using quite involved approaches based on game theory. Stressing the competition issues, a possibility is a policy closer to 'laissez-faire', which probably will accentuate the ongoing trend. Also, in the last few years, prices have received more attention bringing more focus to scale economies and competition.

Because of the conflicting goals, a more unified analysis is necessary. In this article therefore we use a system-wide approach, returning to long neglected questions posted by among others Ofer [3] and Heal [6] some 25-30 years ago. A total cost framework is used to analyse costs associated with various distribution network configurations. We thereby hope to make an important contribution to the knowledge of how to develop our cities in a more sustainable direction and to the grocery distribution research. To our knowledge comprehensive models of this type have not been utilized recently (the last known study with a similar approach is by Widman [7]).

We summarize all relevant costs related to distribution systems with various configurations in a total cost function. The total cost is a sum of costs within firms and costs related to private transports respectively. For the distribution work performed by motorized customers, significant cost shares are captured by vehicle wear and fuel consumption. But important costs are external to the consumers cost function, resulting in a potential market failure. Some of these factors will be accounted for in this analysis, reducing the risk for non-optimal policy recommendations.

\subsection{Scope}

The most important externality in this analysis is congestion. Environmental costs are also relevant but an analysis including for instance the cost of pollution is beyond the scope of this paper. Additional to transport externalities it can be argued that there are less obvious costs associated with the larger stores, e.g. that consumers with limited mobility will be left without accessible service. We also have the potential problem of spatially scattered preferences. A consumer can not exchange a willingness to pay for a specific quantity of a retail service into real consumption, unless there is a critical mass of fellow consumers with similar preferences on that specific spatial market. This problem is accentuated by social dilemmas (see, e.g. Ostrom [8] and Hardin [9]). In a forthcoming paper we show that the transformation from small to larger units could be a 'tragedy of the commons'. However, in this paper we abstain from such problems.

\subsection{Outline}

After a description of the empirical data used in this analysis, a total cost model will be presented. Its components, grocery price and transport cost functions are estimated from empirical data and derived from a specific spatial structure. We define a frequency distribution describing how many times during a specific time period, certain volumes of groceries are bought. This distribution motivates a more complex model including several type/sizes of stores. In section 3.1 we will present and discuss the 
results from the model studies. The last section of the paper is devoted to conclusions and suggestions to further research.

\subsection{Empirical foundation}

In recent years Swedish National Road and Transport Research Institute, VTI, has undertaken several extensive research projects where the behaviour and preferences of grocery consumers has been in focus. A number of surveys covering a multitude of large and middle-sized Swedish cities has resulted in a comprehensive database with information about revealed and stated preferences, e.g. shopping frequency, choice between different store types, bought quantities, transport modes used for shopping, location of stores and consumers etc. In this study knowledge from these surveys forms the foundation for a quite general model where empirical knowledge is used to choose structure and parameter values.

The Swedish consumer agency has compiled a database with price information about 282 commodities from 202 different sized grocery stores. It also includes information about the turnover of each store. The agency has used the prices to compute a monthly cost for a grocery basket suited to a four-person family [10]. The same agency also provides information about mileage costs for cars.

\section{A SIMPLE MODEL}

The model used in this paper consists of consumer behaviour and the costs associated with this under different store nets. Shopping behaviour of households is exogenously determined and defined by the number of times specific amounts of groceries are bought. We assume these trips to be discretely distributed over different grocery volumes. The distribution shows the number of shopping occasions over a specific period of time and the different quantity of groceries bought. We denote this distribution $f(q)$. The total amount of groceries a household buys each period, $Q$, and the number of shopping occasions, $F$, is then:

$$
\begin{aligned}
& Q=\sum_{q=0}^{\infty} f(q) q, \\
& F=\sum_{q=0}^{\infty} f(q) .
\end{aligned}
$$

The demand for groceries is to a large extent determined by basic human needs, so we assume $Q$ to be completely inelastic. Thus the quantity distributed through the modelled system is the same no matter the prices or other configuration parameters. Equation (1) and the number of households, $H$, determine total demand.

The varying size of purchases motivates that stores of different size exist at the same time, serving different purposes. A two-store type situation is illustrated by the solid line (small store) and dashed line (large store) in Fig. 1. The steeper line of the small store indicates a higher price, while the intercept $\beta 2 d$ represents a transport cost. $\beta$ is the relevant kilometre cost, $d$ is the distance between home and store and 2 indicates a round trip.

Clearly it is most efficient to distribute smaller amounts of groceries through the small store, which is located close to consumers, while quantities above $q_{\text {break }}$ should be distributed through the larger store to minimize costs. Even though a store in principle could be of any size, in reality (due to planning policies, city structure etc.) there exist a limited number of store types, each defined to distribute groceries in a specific interval. Suppose that there exist $i$ type of stores, with market areas, which are superimposed on each other. The number of stores of type $i$ is $n_{i}$.

Given $f(q)$ it is now interesting to find cost minimizing combinations of these store types. A number of stores from one or more types will henceforth be referred to as store nets/store configurations. As is obvious from Fig. 1 there are distinct quantity intervals where it is cost efficient to use specific stores. 


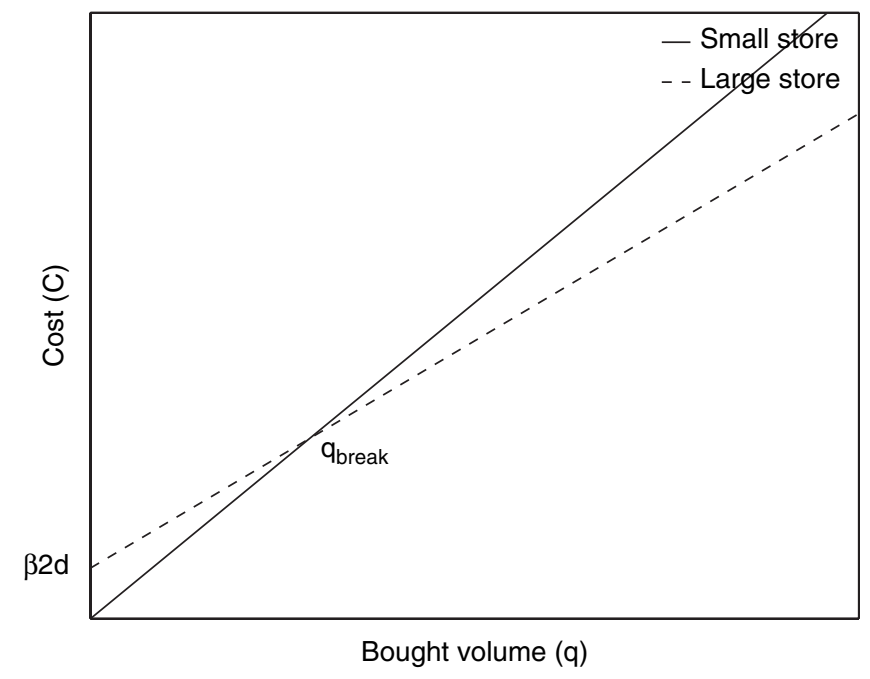

Figure 1: Break even points.

Varying the number/size of stores results in modified intervals so the amount of groceries bought in different stores are endogenous. However, optimization under this condition requires complete specification of $f(q)$. Therefore we assume that households heuristically allocate predetermined shares $w_{i}$ to each store type. The amount of groceries a household buys in store type $i$ is then:

$$
Q_{i}=w_{i} Q \quad \sum_{i=1}^{I} w_{i}=1 .
$$

The volume sold in one single store of type $i$ is:

$$
q_{i}=\frac{H Q_{i}}{n_{i}} .
$$

From the discussion above, it is clear that the price level of different type of stores has to be determined and so do the household distribution cost. These two components correspond to the slopes and intercepts of Fig. 1.

\subsection{Grocery cost}

The data from Swedish Consumer Agency is used to estimate a price/quantity function, where price adjusted turnover is used as a quantity index. The adjustment is made using a price index with base 4,500 SEK (SEK is the abbreviation for the Swedish currency. SEK/euro $=9.57, \mathrm{SEK} / \mathrm{USD}=7.97$ (051101)).

An important assumption is that the price level can be used as an estimate of distributional costs within the grocery distribution firms. In terms of profitability, this implies equal gross margin for all firms. With this assumption we also constrain the analysis from issues regarding industrial structure and competition, since all stores are assumed to be equal in market power.

One might suspect that the relation between quantity and price is reciprocal, resulting in endogenous problems when the price level function is estimated. However, we argue that the quantity is determined 
by real capital investments and that price follows from quantity and the exogenous gross margin. That is, stores are set up to distribute specific real volumes of goods. In a competitive environment, stores can only stay in business with specific quantity/price combinations.

We have estimated a log-linear function that captures the relationship. When fitting the price function to empirical data we also add several dummies to capture some of the regional price differences that have been observed. Without these dummies eqn (4) will reflect the size/price relationship in the cheapest region. The estimation of eqn (4) resulted in a highly significant quantity coefficient $(t=-11.37)$ and a good overall model fit $\left(R^{2}=0.68\right)$.

$$
p_{i}=5943 q_{i}^{-0.067} .
$$

We get the cost for buying groceries by applying eqn (4) for each store type, where quantity is determined by the number of stores of each type, $n_{i}$, and their market shares, $w_{i}$.

\subsection{Household distribution costs}

To specify the transport cost function we assume evenly distributed stores, located in the centre of hexagonal market areas (used by early geographers/economists like Christaller and Lösch). The size of the market area determines the distributed volumes through a single store and, as a consequence of increasing returns, prices. Difference in the number of stores also results in various amounts of shopping related transports. The total distance between a store and the consumers within a hexagonal market area is expressed in eqn (5) where the radius, $r$, is related to the number of evenly distributed stores according to the second row [11]. Out-of-town stores are by definition located on the border of their market areas. Therefore we assume the market areas of out-of-town stores to depend on the number of stores and add up to a hexagonal 'model city'. A limited set of distances was computed related to scenarios with different numbers of this store type.

$$
d_{i}=r_{i}^{3} \sin 30 \cos 30\left[1+\frac{\cos ^{2} 30}{\sin 30}\left\{\frac{1}{2} \ln \left(\frac{1+\sin 30}{\cos 30}\right)\right\}\right], \quad r_{i}=\frac{R}{\sqrt{n_{i}}} .
$$

Social costs for the distribution work carried out by consumers is computed using eqn (5) together with mode shares, $m$, kilometre costs (vehicle, fuel and externalities), $k c$, time cost, $t c$, parking cost, $p c$, and costs for congestion. Distribution work associated with purchases in store type $i$ is denominated $t p_{i}$.

$$
t p_{i}=\sum_{j=c, o} m_{j}\left\{2 d_{i}\left(k c_{j}+\frac{t c}{v_{i, j}}\right)+p c_{i, j}\right\} .
$$

We collect the grocery cost (4) and the household distribution cost (6) in a total cost function. Together with a set of quantity constraints $c_{i}$ that maintain maximum store size, we have a minimization problem (7).

$$
\min _{n_{i}} \sum_{i=1}^{I} w_{i} p_{i}+f_{i} t p c_{i}, \quad \text { such that } \quad q_{i} \leq c_{i}, i=1, \ldots, I .
$$

\section{A REALISTIC CASE}

We analyse a case where total demand is created by 50,000 households $(\mathrm{H}=50,000)$ with an average of four members. Households are equally distributed over a hexagonal 'model city' with radius $5 \mathrm{~km}$ 
and an area of about 65 square kilometres. From Swedish consumer agency we know the households' monthly demand of groceries, $Q$, defined in a specific price index, to be 4,500 .

Even if in theory any number of store types could exist, in reality stores can be classified into a limited set of groups. Most real grocery stores can be classified into small residential area stores, medium sized district centre stores or large stores with either central or out-of-town locations [1]. This motivates a model structure with four different type of stores $(i=1, \ldots, 4)$. Residential area stores $(i=1)$ are units which provide easily accessible service. Their size is limited though by various technical and legal constraints. Experience shows that an upper limit for annual turnover in residential area stores is about 20 million SEK. We will impose this as a constraint in the model. In district centres space is available allowing somewhat larger stores. District centre stores $(i=2)$ are limited to a maximum of 80 million SEK. The third and fourth types, large city centre stores $(i=3)$ and out-of-town establishments $(i=4)$ are both unrestricted in this respect, due to the fact that they are located in environments that are fully devoted to commercial activities.

The store types are combined to four grocery store systems. The first consists of residential stores only, the second of residential and district centre stores. The third and fourth system includes city centre stores and out-of-town establishments. Within these quite flexible store and system definitions we optimize to achieve the lowest possible total cost. Varying the number of each store type results in a continuous set of scenarios with various total costs and various amounts of consumer transport work. At the optimal solution the total cost will correspond to a situation where the distribution system would be adjusted to more flexible settings than any real city can display in the short run. Figure 2 illustrates the structure of three store type net.

Table 1 is based on empirical research. From our earlier studies we know the total number of monthly shopping trips $(F=16)$. We also know that shopping is roughly divided in well-planned regular shopping and supplementary purchases. In net 1 all shopping trips and the full quantity are allocated to the residential area stores. For the more complex nets we will assume that the larger stores

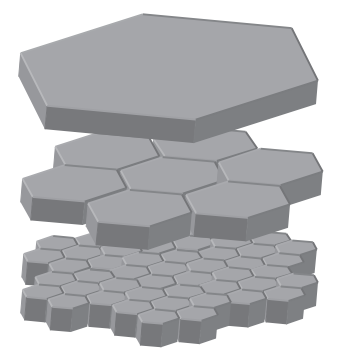

City center/Out of town stores

District center stores

Residential area stores

Figure 2: Spatial structure.

Table 1: Consumer behaviour.

\begin{tabular}{|c|c|c|c|c|c|c|c|c|}
\hline \multirow[b]{2}{*}{ Store net } & \multicolumn{4}{|c|}{ Trip frequency $f$} & \multicolumn{4}{|c|}{ Market share $w$} \\
\hline & 1 & 2 & 3 & 4 & 1 & 2 & 3 & 4 \\
\hline Residential area & 16 & 9 & 5 & 5 & 1 & 0.4 & 0.2 & 0.2 \\
\hline District centre & 0 & 7 & 5 & 5 & 0 & 0.6 & 0.3 & 0.3 \\
\hline City centre & 0 & 0 & 6 & 0 & 0 & 0 & 0.5 & 0 \\
\hline Out-of-town & 0 & 0 & 0 & 6 & 0 & 0 & 0 & 0.5 \\
\hline
\end{tabular}


are used for large volume shopping while smaller supplementary purchases are made in residential area stores. The relation between market share and shopping frequency show larger amounts per shopping occasion in larger stores.

We use a time cost $(t c)$ of $26 \mathrm{SEK} / \mathrm{h}$, which is the value that Swedish transport authorities use for transport investment analysis [12]. We have evaluated the model with two different costs, 5 and 20 SEK, per car kilometre. This cost includes fuel consumption and depreciation (Swedish consumer agency estimates the kilometre cost of a new Volvo V70 that the owner keeps for 5 years to be 3.5 SEK, www.konsumentverket.se, access date 05/02/2003). The lower level is referred to as the base case and the higher as the high cost case. The latter corresponds to an extreme situation where traffic is close to the roads' capacity limit with heavy congestion as a result. The motivation for using these two scenarios is to assess the impact from traffic congestion time costs on the optimal grocery store net. For other transport modes (e.g. walk, bike, public transport) we use $15 \mathrm{SEK} / \mathrm{km}$. Even if several means of transport are used by consumers, we only discriminate between car and other modes. The average speed for car trips is assumed to be $30 \mathrm{~km} / \mathrm{h}$. Trips performed by foot or by other transport modes are assumed to have an average speed of $10 \mathrm{~km} / \mathrm{h}$. As the high cost cases are motivated by costs caused by congested transport networks, one could object that speed should be reduced for the same reason. We argue however, that this would result in a non-motivated double compensation. The car share $\left(m_{c, i}\right)$ varies between different store types. For residential areas the share of shopping trips made by car is 25 per cent. For district centre stores the share is 50 per cent. For city centre stores and out-of-town establishments the shares are assumed to be 75 and 100 per cent respectively.

Based on index adjusted information from Jansson [13] we use a parking cost of $90 \mathrm{SEK} / \mathrm{h}$ for inner city shopping and $10 \mathrm{SEK} / \mathrm{h}$ in other store types. The high inner city rate corresponds to the alternative cost of a parking lot in large city parking spaces with a 50 per cent occupancy rate. The parking cost can also be interpreted as an approximation of several non-specified costs associated with inner city shopping establishments. We are also aware of the well-known fact that work performed by private persons always seems misleadingly cheap, since no taxes are imposed. To rectify for this tax wedge, we add $3 \mathrm{SEK} / \mathrm{km}$ for the grocery distribution transports performed by consumers [14].

\subsection{Analysis}

As are shown in Table 2, in the base case lowest total cost is achieved within net 4, showing that out-of-town establishments are cost efficient when traffic load is below capacity limit. The second and third most cost efficient networks respectively are 2 and 1 where costs are slightly higher. In both these networks size constraints are active, which indicates that these settings suffer from the physical limitations imposed when retailing businesses are interposed among residential properties. In these nets residential area stores and districts centre stores distribute all groceries. Such quantities are more

Table 2: Results - total costs.

\begin{tabular}{lcc}
\hline & Base case & High cost case \\
\hline Net 1 & 5,010 & 5,041 \\
Net 2 & 4,948 & 5,046 \\
Net 3 & 5,059 & 5,336 \\
Net 4 & 4,903 & 5,331 \\
\hline
\end{tabular}


Table 3: Optimal number of stores.

\begin{tabular}{|c|c|c|c|c|c|c|c|c|}
\hline \multirow[b]{2}{*}{ Store net } & \multicolumn{4}{|c|}{ Base case } & \multicolumn{4}{|c|}{ High cost case } \\
\hline & 1 & 2 & 3 & 4 & 1 & 2 & 3 & 4 \\
\hline Residential area & 135 & 54 & 27 & 27 & 135 & 54 & 27 & 27 \\
\hline District centre & 0 & 21 & 11 & 11 & 0 & 21 & 14 & 14 \\
\hline City centre & 0 & 0 & 3 & 0 & 0 & 0 & 9 & 0 \\
\hline Out-of-town & 0 & 0 & 0 & 5 & 0 & 0 & 0 & 5 \\
\hline
\end{tabular}

efficiently handled with units of a larger scale than what will be allowed within city locations. The active constraints show that marginal in-firm cost reductions due to larger units still counterbalance the additional cost for consumer distribution work. This proves that there is a strong incentive for market concentration driven by economies of scale, but that residential area and district centre locations impedes these benefits from being utilized.

Increasing costs for private cars dramatically, to correspond to our high cost case, means that the most cost efficient store net doesn't include out-of-town establishments any longer. Instead a net with residential area stores only will be least costly, followed by network 2 . Hence, when traffic exceeds capacity levels, with congestion costs as a result, distribution networks with residential area and district centre stores are socially superior to networks including out-of-town establishments. Still, the stores in net 1 and 2 will reach their maximum size. Thus, even when the kilometre cost is high the marginal extra transport costs associated with a reduction of the number of stores would be compensated by reductions of in-store costs. Physical constraints, however, make such an adjustment hypothetical. The third most cost efficient network under these circumstances is net 4, i.e. the out-oftown configuration. The most expensive is the network including large inner city stores. As opposed to network 1 and 2, these more complex networks are adjusted in terms of store number (see Table 3), with reduction in private transports as a result.

A distinct result is that store net 3, i.e. the net with large inner city stores, in both cases has the highest total cost. This is due to the high parking cost in central areas of cities. This result is reinforced by considering unaccounted factors like land rents, space restrictions and congestion that clearly affects net 3 worst. This is in accordance with observed historical facts. The phase corresponding to net 3 was quite short. Large grocery stores in inner cities soon became too costly and were replaced by out-of-town establishments due to the increasing car usage among customers.

\section{CONCLUSIONS}

Let us now return to the increasing-returns illusion hypothesis that we addressed in the beginning of this paper. Our conclusion is that the increasing returns are, under most conditions, not an illusion, but due to external costs somewhat exaggerated. In cases where traffic load is moderate there is convincing evidence that the ongoing transformation of the grocery distribution and retail industry is welfare enhancing through a more cost effective distribution system including the work performed by households. The costs associated with the transport and time used by consumers are more than well compensated by the scale economies related to larger stores. The additional costs from increased private car traffic are under these circumstances small enough to make a spatially sparse store net cost efficient where a few out-of-town establishments have a prominent role. When the transport network is congested however, we have a situation closer to the scenario with an increasing-returns illusion. Now, out-of-town locations are too costly socially, due to the higher kilometre cost. However, even 
with these kilometre cost levels, real scale economies are not exhausted. In this situation further concentration of networks with stores in residential areas and district centres is instead impeded by physical limitations due to the location of stores close to houses in residential areas.

An interesting result is also that if consumers were only partially rational, focusing on price but only to a limited extent on transport related costs and time usage, it would lead to a store network, which is sparser than the socially optimal. Considering prices only would lead to the obviously wrong conclusion that a large market share for out-of-town establishments is beneficial in every case. This one dimensional perspective, leading to the increasing-returns illusion is unfortunately easily found in reports from competition authorities analysing the grocery retail market.

An implicit condition for the analysis above is that the generated car traffic flows can be handled by the transportation system with a balanced capacity utilization. Even if we use scenarios associated with different levels of transport network flows, these levels are not assumed to be affected by the grocery shopping related traffic per se. Given that this network is already in place, i.e. we have invested in a car-adapted city, we have shown that out-of-town establishments are cost efficient. Only a severely congested transportation network can alter the outcome in favour of a denser store net with smaller stores and shorter distances. This is in a sense an obvious result. Given that the costs for the infrastructure, i.e. the street network, can be regarded as sunk costs, it would be foolish not to use it to save costs and rationalize the production in other sectors.

A relevant issue that follows naturally from the discussion above is whether it was a strategic mistake to give private cars their superior position in the first place. It is not necessary to discuss the 'car-city question' in whole to understand that these strategic dimensions can have implications for the functioning of the grocery retail market from a social point of view. From a policy perspective the results of this study clearly suggest that issues regarding local service should be an integral part of strategic urban transport planning. With infrastructure and transportation systems that enable easy and affordable access to all the city, a significant number of people will find it optimal to use large stores for grocery shopping. Restrictive policies at the more detailed level will clearly be ineffective since they are counteracted by forces released by more strategic choices.

A related problem is that there might be an unmet demand for local retail service. We plan to address this issue in a forthcoming paper. Another suggestion for future research is to include pollution and other environmental costs in the model framework presented here.

\section{REFERENCES}

[1] Svensson, T., Dagligvarudistributionens strukturomvandling - Drivkrafter för städers utformning och miljö, Linköping Studies in Arts and Science 179, Linköping University, 1998 (in Swedish).

[2] Asplund, M. \& Friberg, R., Food prices and market structure in Sweden. Scandinavian Journal of Economics, 104(4), pp. 547-566, 2002.

[3] Ofer, G., Returns to scale in retail trade. The Review of Income and Wealth, 19(4), pp. 263-384, 1973.

[4] Hagson, A., Effekter av externetablerad handel, särskilt dagligvaruhandel, på trafikarbete och miljö-En kunskapsöversikt, Technical report, Chalmers University of Technology, 2003 (in Swedish).

[5] Ljungberg, C., Modig, K., Neergaard, K. \& Rosqvist, L.S., Externa och halvexterna affärsetableringar -Litteraturstudie och kartläggning, Technical Report 148, Vägverket, 2003 (in Swedish).

[6] Heal, G., Spatial structure in the retail trade: a study in product differentiation with increasing returns. Bell Journal of Economics, 11(2), pp. 565-583, 1980. 
[7] Widman, L., Alternativa distributionssystem-En samhällsekonomisk modellstudie av dagligvarudistributionen, Almqvist och Wiksell International, 1976 (in Swedish).

[8] Ostrom, E., Collective action and the evaluation of social norms. Journal of Economic Perspectives, 14(3), pp. 137-158, 2000.

[9] Hardin, G., The tragedy of the commons. Science, 162(3859), pp. 1243-1248, 1968.

[10] Konsumentverket, Hushållens matkostnader, Rapport 15, 1999 (in Swedish).

[11] Nijkamp, P. \& Paelinck, J.H.P., Operational Theory and Method in Regional Economics, Saxon House, 1978.

[12] SIKA, Översyn av samhällsekonomiska kalkylprinciper och kalkylvärden på transportområdet, Rapport 6, Statens institut för kommunikationsanalys, 1999 (in Swedish).

[13] Jansson, J.O., Parkerings och trafikpolitik för humanare innerstadsmiljö, Byggforskningsrådet, 1987 (in Swedish).

[14] Jansson, J.O., Transportekonomi och livsmiljö, SNS Förlag, 1996 (in Swedish). 